\title{
A cultural-self learning design platform
}

Professor John Clayton

Mark Laws Endowed Chair, Te Whare Wananga o Awanuiārangi

John.clayton@wananga.ac.nz

Submission Type: Brief Presentation (20mins + 10minsQ\&A)

Keywords: learning design, cultural conceptuality, cultural self

\section{Abstract:}

Even though it is acknowledged culture pervades learning and that emotions and context play a significant role in the learning process, Eurocentric instructional design models are based solely on cognitive, social and pedagogical approaches. These approaches do not contextualize the learning experience, i.e. they do not address cultural conceptuality (Cliver, 2013). Knowing a wide range of cultural influences impact on the engagement and success of adult learners, learning environments need to encourage learners to acknowledge and validate their cultural being. This identity - knowing who they are, where they come from and what factors influence their engagement - provides learners with a positive setting they feel comfortable in. These context sensitive, learner centric environments provide the fundamental confidence needed for learners to believe they can succeed in achieving their educational goals (Johnson, 2012). Therefore, designers need to provide context sensitive learning experiences, performance tasks and assessments that build familiarity, confidence and trust (Kennedy, 2013).

This presentation will describe how Te Whare Wananga o Awanuiārangi has integrated the theories of cognitive load, social cognition, transformative learning and the processes of holistic assessment, the Ranga Framework, personal learning planning and noho delivery into a holistic cultural-self learning design platform. This integration of theory and process provides the foundation for a unique learning design approach, based on the concepts of feedforward, feedback, assessment and reflection, to be established (Clayton et al, 2019). The presentation will demonstrate how this approach can be applied in a learning management system segmented into seven interwoven but discrete spaces,

- Welcome / Mihi Whakatau: This space is focused on participants cultural self-enabling them to become familiar and comfortable with the approach to be used.

- Induction / Rangatahi: During this stage opportunities are provided for learners to clarify and understand these learning outcomes and performance criteria associated with the micro-credential.

- Engagement / Rangahau: During this stage learning activities are designed to build upon, rather than be independent of, learner's current knowledge and beliefs.

- Mātauranga /Performance: During this stage opportunities will be provided for learners to engage in assessment tasks that confirm their capabilities.

- Rangatira / Capstone: During this stage participants will, with the guidance of tutors and peers, reflect on the outcomes of their learning activities and identify the learning strategies that were successful for them.

- Arotakenga: Evaluation: During this stage evidence will be collected on the impact of the microcredential on stakeholders.

NB: Participants are encouraged to bring their own devices as they will be provided with editing access to a working demonstrator within a Learning Management System.

\section{References}

Clayton, J., Gao, Y., Elliott, R., Geng, F. \& Yang, J. (2019) Micro-credentials in professional and technical vocational education and training: A cultural self-approach, Positional Paper, Awanuiārangi Press, Whakatane, New Zealand

Cliver, C., (2013), Comparison of Instructional Design Models, Course Notes - MEDT 7461, The University of West Georgia. 
Johnson, T. (2012). Self-assessment: A means to enhance academic self-efficacy in year 12 mathematics, (Masters Thesis). Massey University, Manawatu, New Zealand. Retrieved from https://mro.massey.ac.nz/bitstream/handle/10179/3310/02_whole.pdf?sequence=1\&isAllowed=y

Kennedy, C. P. (2013). Indigenizing student-centred learning: A western approach in an indigenous educational institution. Journal of International Education Research, 9(1), 1. Retrieved from

https://search.proquest.com/docview/1433387182? accountid=33567 